\title{
Pengolahan Minyak Jelantah Menggunakan Membran Poliamida/Titanium Dioksida/Arang Aktif Kulit Durian
}

\author{
Rika Endara Safitri ${ }^{1 *}$, Ria Sheftiana Rusli Hayaati ${ }^{1}$ \\ ${ }^{1}$ Program Studi Kimia, Fakultas Matematika dan Ilmu Pengetahuan Alam, Universitas PGRI \\ Banyuwangi, Jawa Timur, Indonesia
}

Corresponding Author: Rika Endara Safitri

dara_syahdan@yahoo.com

Received: March 2021

Accepted: August 2021

Published: September 2021

(ORika Endara Safitri et al. This is an open-access article distributed under the terms of the Creative Commons Attribution License, which permits unrestricted use, distribution, and reproduction in any medium, provided the original author and source are credited.

\begin{abstract}
Processing of wasted cooking oil uses the photocatalyst method with metal catalysts and zeolites to reduce organic compounds. In this study, researchers used activated charcoal from durian skin and titanium dioxide embedded in a polyamide membrane as an adsorbent which was used as a medium for processing wasted cooking oil. The purpose of this study was to determine the effect of processing used cooking oil using a membrane of polyamide/titanium dioxide/durian peels activated charcoal on changes in the characteristics of wasted cooking oil. Based on the results of research on the processing of wasted cooking oil with a membrane of polyamide/titanium dioxide/activated charcoal from durian peels, there was an increase in water content by $10.21 \%$, a decrease in free fatty acids by $33.75 \%$, a decrease in the peroxide number by $18.33 \%$. Used cooking oil that has passed through the membrane has a decrease in \%Transmission for the functional groups of $\mathrm{C}-\mathrm{H}$ alkenes, $\mathrm{C}-\mathrm{O}$ esters, and $\mathrm{C}-\mathrm{H}$ alkanes. In the analysis of the compound content by mass spectrophotometry, it was found that the content of the methyl ester compound with the C17 and C19 chains was close to the composition of the biodiesel constituents.
\end{abstract}

Keywords: polyamide, titanium dioxide, wasted cooking oil, actived charcoal

\section{Pendahuluan}

Minyak goreng merupakan salah satu kebutuhan pangan yang sering digunakan dalam proses pengolahan makanan. Masyarakat di Indonesia umumnya menggunakan minyak goreng dengan bahan dasar kelapa sawit. Hal ini dikarenakan minyak goreng dari kelapa sawit memiliki keunggulan dari segi harga yang ekonomis serta mengandung senyawa yang bermanfaat untuk tubuh seperti senyawa karoten dan tokoferol (sumber vitamin E). Manfaat minyak goreng dari kelapa sawit adalah sebagai salah satu bahan baku pembuatan biodiesel melalui proses esterifikasi[1]. Minyak goreng sering digunakan secara berulang sehingga menghasilkan warna gelap dan berbau yang secara umum disebut minyak jelantah. Minyak jelantah diakibatkan adanya proses oksidasi yang menghasilkan senyawa aldehida, keton, hidrokarbon, alkohol, lakton, serta senyawa aromatis dan polimerisasi ${ }^{[2]}$.

Minyak jelantah merupakan salah satu limbah rumah tangga yang masih dapat dimanfaatkan kembali baik sebagai bahan baku biodiesel dan bahan baku pembuatan sabun. Beberapa penelitian menggunakan proses adsorpsi untuk pengolahan minyak jelantah untuk 
menurunkan bilangan asam dan bilangan peroksida sesuai dengan standar mutu minyak goreng (SNI 7709:2012)[3] dan beberapa peneliti menggunakan katalisator untuk mengalihfungsikan minyak jelantah menjadi biodiesel (SNI 7182:2015) ${ }^{[4]}$. Adsorben digunakan sebagai media penyerap kotoran yang terdapat pada minyak, namun proses ini diperlukan pengadukan untuk peningkatkan luas permukaan serap dan dilanjutkan dengan penyaringan untuk memisahkan kembali minyak dengan adsorben.

Berdasarkan penelitian Wulyoadi, dkk[5], penggunaan membran dapat menurunkan bilangan asam dan bilangan peroksida pada minyak jelantah. Beberapa peneliti terdahulu juga telah melakukan penelitian pengolahan minyak jelantah menggunakan adsorben dari bahan alami dengan memanfaatkan produk samping atau limbah pertanian, seperti ampas tebu ${ }^{[6]}$, arang aktif dari sabut kelapa ${ }^{[7]}$, karbon aktif dari biji kelor ${ }^{[8]}$, ampas pati aren dan bentonit ${ }^{[9]}$, arang aktif dari kulit salak ${ }^{[10]}$, dan arang kulit durian ${ }^{[11]}$. Beberapa penelitian lain, memanfaatkan zeolit alam sebagai bahan adsorben seperti yang dilakukan oleh Widayat, $\mathrm{dkk}^{[2]}$. Tiap jenis adsorben memiliki selektivitas dalam mengadsorpsi komponen tertentu yang ada dalam minyak goreng bekas. Berdasarkan penelitian Kaltsum, dkk ${ }^{[12],}$ penggunaan titanium dioksida dalam pengolahan minyak jelantah dibawah sinar matahari dapat menurunkan bilangan asam hingga $67.10 \%$ dan bilangan peroksida hingga $79.15 \%$.

Pada penelitian ini, penggunakan arang aktif dari kulit durian dan titanium dioksida yang teremban pada membran poliamida diharapkan dapat meningkatkan efektifitas pengolahan minyak jelantah secara adsorbsi. Senyawa organik dalam minyak jelantah akan tereduksi menjadi senyawa ester dengan fotokatalisator titanium dioksida sehingga dapat meningkatkan nilai manfaat dari minyak jelantah sebagai biodiesel. Penggunaan membran poliamida sebagai bahan pengemban agar dapat meningkatan luas permukaan sehingga proses adsorbsi dapat dilakukan dengan maksimal. Penelitian ini bertujuan untuk mengetahui kemampuan membran poliamida/titanium dioksida/arang aktif kulit durian dalam pengolahan minyak jelantah diukur dari kadar air, asam lemak bebas, dan bilangan peroksida, Fourier Transform Infra-Red (FTIR) dan Gas Chromatography-Mass Spectroscopy (GC-MS).

\section{Metodologi Penelitian}

\section{Bahan kimia}

Bahan-bahan yang digunakan pada penelitian ini adalah benang nilon putih merek owl crown, titanium dioksida teknis $\left(\mathrm{TiO}_{2}\right)$, aquades $\mathrm{dm}$ diproduksi oleh pt. brataco-malang, arang aktif kulit durian, indikator amilum, kertas $\mathrm{pH}$ universal, aluminium foil, kertas saring. Beberapa bahan kimia buatan Merck yaitu aseton(pa), asam klorida 37\%, natrium hidroksida, klorofom, asam sulfat $97 \%$, asam asetat glasial, etanol $96 \%$, fenolftalein, kalium iodida, natrium tiosulfat, kalium iodat, asam oksalat.

\section{Peralatan}

Alat-alat yang digunakan dalam penelitian ini adalah peralatan gelas laboratorium, satu set alat pengaduk magnetik, neraca analitik Ohaus PA 214 diproduksi oleh Ohaus CorporationUSA, Oven listrik UN 55 diproduksi oleh Universal Oven Memmert-Jerman.

\section{Prosedur penelitian}

\section{Pembuatan tabung membran poliamidal titanium dioksida/arang aktif kulit durian}

Pembuatan arang aktif dari kulit durian dan perbandingan komposisi mengikuti prosedur penelitian dari Safitri, $\operatorname{dkk}^{[13]}$, dimana didapatkan kondisi optimal dengan perbandingan benang nilon : titanium dioksida : arang aktif kulit durian $=2.5: 0.45: 0.15(\mathrm{~g})$. Pembuatan tabung membran poliamida/ titanium dioksida/arang aktif kulit durian dilakukan secara bertahap. Komposisi 1 Lapisan larutan membran poliamida/titanium dioksida/ arang aktif kulit durian terbuat dari benang nilon $2.5 \mathrm{~g}, \mathrm{HCl} 25 \% 10 \mathrm{~mL}$, aseton $1 \mathrm{~mL}$, titanium dioksida $0.45 \mathrm{~g}$, dan arang aktif kulit durian 0.15 g. Pengadukan dilakukan selama 2 jam pada suhu ruang dan langsung dicetak 
dalam tabung plastik dari botol bekas. Pada saat proses inversi fasa, ujung tabung plastik bagian bawah diberi air terlebih dahulu agar membran tidak keluar tabung dan selanjutnya air dimasukkan perlahan pada bagian atas tabung. Membran yang tercetak pada tabung plastik dibiarkan selama 12 jam pada suhu ruang dan air pada tabung keluar seluruhnya. Membran yang terbentuk disiram air lagi hingga 2 kali pengulangan. Tabung membran dikeringkan terlebih dahulu pada suhu ruang sebelum ditambahkan lapisan membran lagi. Tabung membran dibuat dengan 5 lapisan, 10 lapisan, dan 15 lapisan untuk mengetahui pengaruh banyaknya lapisan pada pengolahan minyak jelantah. Setelah tabung membran poliamida/ titanium dioksida/arang aktif kulit durian selesai dibuat sesuai jumlah lapisan, tabung membran dinetralisasi dengan larutan $\mathrm{NaOH}$ $0.01 \mathrm{M}$ hingga tingkat keasaman $(\mathrm{pH})$ larutan yang keluar tabung mendekati 7. Proses netralisasi tabung membran diakhiri dengan mengaliri akuades dan selanjutnya dikeringkan pada suhu ruang. Membran yang terbentuk dianalisis gugus fungsinya secara FTIR.

\section{Aplikasi pengolaham minyak jelantah menggunakan tabung membran poliamidal titanium dioksida/arang aktif kulit durian}

Tabung yang telah dinetralisasi dan dikeringkan diatur seperti Gambar 1, dimana tabung ditahan oleh penyangga sehingga minyak jelantah yang telah melewati membran poliamida/titanium dioksida/arang aktif kulit durian dapat langsung ditampung pada wadah. Minyak jelantah yang dimasukkan pada tabung membran poliamida/titanium dioksida/arang aktif kulit durian sebanyak $200 \mathrm{~mL}$ dan dibiarkan melewati membran seluruhnya tanpa memperhatikan lamanya proses pengolahan. Minyak jelantah yang telah melewati membran disebut minyak lapis (sesuai jumlah lapisan tabung membran yang digunakan) kemudian dianalisis kadar air, asam lemak bebas, dan bilangan peroksidanya. Minyak lapis dengan penurunan bilangan asam dan bilangan peroksida tertinggi, dilakukan analisis FTIR untuk dibandingkan dengan minyak jelantah awal.

\section{Pengukuran}

\section{Analisis kadar air pada minyak jelantah}

Analisis kadar air mengikuti SNI 7709:2012 dengan metode mengovenan. Wadah aluminium beserta tutupnya yang akan digunakan dioven terlebih dahulu pada suhu $130{ }^{\circ} \mathrm{C}$ selama 30 menit dan didinginkan dalam desikator selama 20 menit, kemudian dilakukan penimbangan sebagai massa wadah $\left(\mathrm{M}_{\mathrm{w}}\right)$. Sampel minyak sebanyak $2 \mathrm{~g}$ diletakkan pada wadah aluminium, ditutup, dan ditimbang sebagai massa minyak awal (M0).

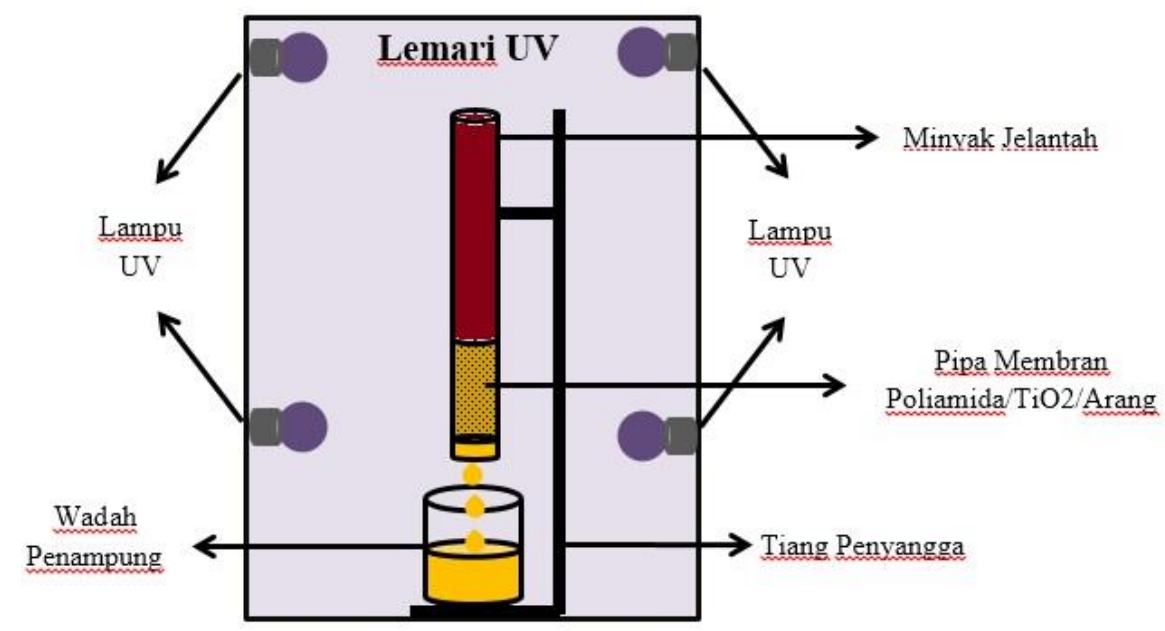

Gambar 1. Susunan alat aplikasi pengolahan minyak jelantah dengan tabung membran poliamida/titanium dioksida/arang aktif kulit durian dalam lemari Ultraviolet (UV). 
Wadah aluminium berisi sampel minyak dan tutupnya dioven pada suhu $130{ }^{\circ} \mathrm{C}$ selama 30 menit dalam kondisi terbuka. Setelah 30 menit, tutup wadah minyak, pindahkan ke desikator, dan didinginkan selama 20 menit. Selanjutnya wadah minyak dan tutup ditimbang sebagai massa akhir $\left(\mathrm{M}_{1}\right)$. Perhitungan kadar air menggunakan persamaan berikut:

$$
\text { Kadar air }(\%)=\frac{\mathrm{M}_{0}-\mathrm{M}_{1}}{\mathrm{M}_{0}-\mathrm{M}_{\mathrm{w}}} \times 100 \%
$$

\section{Analisis asam lemak bebas pada minyak jelantah}

Analisis asam lemak bebas mengikuti SNI 7709:2012[3], dimana 10-50 g sampel minyak dilarutkan dengan $50 \mathrm{~mL}$ etanol hangat dan ditambahkan 5 tetes larutan fenolftalein sebagai indikator. Campuran larutan dititrasi dengan natrium hidroksida $0.1 \mathrm{~N}$ hingga terbentuk warna merah muda. Perhitungan asam lemak bebas dari sampel minyak menggunakan persamaan berikut:

$$
\mathrm{ALB}=\frac{25.6 \times \mathrm{V} \times \mathrm{N}}{\mathrm{W}}
$$

Dimana:

$\mathrm{ALB}=$ asam lemak bebas (sebagai asam palmitat;

$\mathrm{V}=$ volume natrium hidroksida $0.1 \mathrm{~N}$ yang diperlukan $(\mathrm{mL})$;

$\mathrm{N}=$ normalitas larutan natrium hidroksida (N);

$\mathrm{W}=$ massa sampel minyak yang diuji (g).

\section{Analisis FTIR}

Analisis FTIR dilakukan di Laboratorium Sentral (Mineral dan Material Maju), Universitas Negeri Malang. Analisis FTIR dilakukan untuk membran poliamida/titanium dioksida/arang aktif kulit durian, minyak jelantah, minyak lapis optimum.

\section{Analisis GC-MS}

Analisis GC-MS dilakukan di Laboratorium Kimia Organik, Fakultas Matematika dan Ilmu Pengetahuan Alam, Universitas Gajah Mada. Analisis GC-MS dilakukan pada minyak lapis optimum (minyak jelantah sesudah perlakuan).

\section{Hasil dan Diskusi}

Membran poliamida dari benang nilon dicampurkan dengan titanium dioksida dan arang aktif kulit durian dan dilakukan pencetakan dengan metode inversi fasa. Penelitian tentang pengaruh penambahan massa titanium dioksida dan massa arang aktif kulit durian pada kemampuan daya serap membran poliamida/titanium dioksida/arang aktif kulit durian telah dilakukan oleh Safitri, $\mathrm{dkk}^{[13]}$. Berdasarkan penelitian tersebut, membran poliamida/ titanium dioksida/arang aktif kulit durian dalam kondisi optimum dapat melakukan mengadsorpsi minyak hingga $250 \%$ (b/b) dari luas permukaannya (Tabel 1). Peningkatan ini cukup signifikan untuk meningkatkan kemampuan membran dalam mengolah minyak jelantah dengan metode fotokatalis dalam ruang UV.

Pada aplikasi pengolahan minyak jelantah dengan menggunakan membran poliamida/ titanium dioksida/arang aktif kulit durian, peneliti memiliki 3 jenis tabung yang memiliki perbedaan pada jumlah membran yang digunakan yaitu 5 lapisan 10 lapisan, dan 15 lapisan. Minyak jelantah diolah dalam lemari UV seperti Gambar 2a. Lama waktu proses pengolahan minyak jelantah dengan metode ini dilakukan hingga seluruh minyak melewati membran. Pada gambar $2 \mathrm{~b}$ menampilkan minyak hasil perlakuan, dimana semakin banyak lapisan yang dilalui maka semakin jernih minyak jelantah yang dihasilkan.

Tabel 1. Data persentase daya serap membran poliamida ${ }^{[13]}$

\begin{tabular}{ccc}
\hline \multicolumn{1}{c}{ Membran Poliamida } & Daya Serap Air (b/b \%) & Daya Serap Minyak (b/b \%) \\
\hline Tanpa titanium dioksida + tanpa arang aktif & 158.98 & 143.13 \\
Titanium dioksida + arang aktif & 304.10 & 250.27 \\
\hline
\end{tabular}




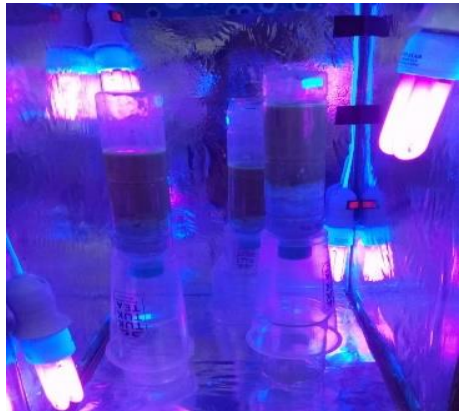

(a)

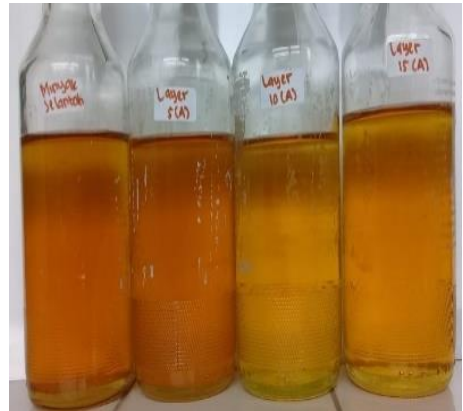

(b)

Gambar 2. (a) Aplikasi pengolahan minyak jelantah dengan menggunakan membran poliamida/ titanium dioksida/arang aktif kulit durian dalam lemari UV; (b) hasil pengolahan minyak jelantah.

Minyak jelantah yang telah melewati tabung membran selanjutnya dinamakan sesuai dengan jumlah lapis membran yang dilewati yaitu minyak 5 lapis, minyak 10 lapis, dan minyak 15 lapis. Minyak hasil perlakuan dianalisis berdasarkan kadar air, asam lemak bebas, dan bilangan peroksidanya. Berdasarkan Tabel 2 menunjukkan semakin banyak lapisan membran yang digunakan pada pengolahan minyak jelantah maka menurunkan nilai asam lemak bebas dan bilangan peroksida. Penurunan ini disebabkan meningkatnya kemampuan membran dalam proses reduksi senyawa organik dari minyak jelantah. Hal ini berbanding terbalik dengan kadar air, dimana semakin banyak lapisan membran yang digunakan maka semakin meningkat pula kadar airnya. Peningkatan kadar air ini telah dijelaskan pada penelitian Ibhadon and
Fitzpatrick bahwa reaksi reduksi dari senyawa organik pada minyak jelantah oleh titanium dioksida yang diberi sinar UV menghasilkan air ${ }^{[14]}$.

Berdasarkan Tabel 2 diketahui nilai asam lemak bebas pada minyak yang melewati 15 lapisan membran memiliki penurunan yang lebih baik yaitu sebesar $33.75 \%$. Nilai asam lemak bebas pada minyak 15 lapis yaitu $0.56 \mathrm{mg} \mathrm{KOH} / \mathrm{g}$ dimana nilai tersebut mendekati nilai batas kandungan asam lemak bebas pada biodiesel yaitu $0.5 \mathrm{mg} \mathrm{KOH/g} \mathrm{(sesuai} \mathrm{SNI} \mathrm{7182:2015[4]).}$ Jika dilihat dari nilai massa jenis dari minyak 15 lapis yaitu $0.88 \mathrm{Kg} / \mathrm{m}^{3}$, maka kecenderungan hasil pengolahan dengan metode ini adalah biodiesel yang memiliki massa jenis berkisar $0.85-0.89 \mathrm{Kg} / \mathrm{m}^{3}$.

Tabel 2. Hasil analisis minyak jelantah yang diproses dengan membran poliamida/titanium dioksida/arang aktif kulit durian

\begin{tabular}{|c|c|c|c|c|c|c|c|}
\hline Perlakuan & $\begin{array}{c}\text { Massa } \\
\text { Jenis } \\
\left(\mathrm{Kg} / \mathrm{m}^{3}\right)\end{array}$ & $\begin{array}{c}\text { Kadar } \\
\text { Air } \\
(\% \mathrm{~m} / \mathrm{m})\end{array}$ & $\begin{array}{l}\text { Peningkatan } \\
\text { Kadar Air (\%) }\end{array}$ & $\begin{array}{c}\text { Asam } \\
\text { Lemak } \\
\text { Bebas } \\
\text { (mg } \\
\mathrm{KOH} / \mathrm{g})\end{array}$ & $\begin{array}{c}\text { Penurunan } \\
\text { Asam } \\
\text { Lemak } \\
\text { Bebas (\%) }\end{array}$ & $\begin{array}{c}\text { Bilangan } \\
\text { Peroksida } \\
\text { (mek } \\
\mathrm{O}_{2 / \mathrm{Kg})}\end{array}$ & $\begin{array}{c}\text { Penurunan } \\
\text { Bilangan } \\
\text { Peroksida } \\
(\%)\end{array}$ \\
\hline Minyak jelantah & 0.91 & 0.15 & 0.00 & 0.84 & 0.00 & 19.70 & 0.00 \\
\hline Minyak 5 lapis & 0.89 & 0.15 & 2.83 & 0.76 & 9.58 & 18.83 & 4.39 \\
\hline Minyak 10 lapis & 0.88 & 0.16 & 5.11 & 0.71 & 16.13 & 16.23 & 17.58 \\
\hline Minyak 15 lapis & 0.88 & 0.16 & 10.21 & 0.56 & 33.75 & 16.08 & 18.33 \\
\hline
\end{tabular}


Untuk memastikan kandungan biodiesel, maka minyak 15 lapis dilakukan analisis lebih lanjut dengan melakukan FTIR dan GC-MS.

Analisis gugus fungsi dengan FTIR pada minyak 15 lapis (minyak sesudah perlakuan/garis merah) dan minyak jelantah (minyak sebelum perlakuan/garis hijau) ditampilkan pada Gambar 3. Berdasarkan Gambar 3, spektrum pada kedua sampel minyak memiliki garis yang hampir sama, namun terdapat perbedaan pada kecuraman \% (transmisi). Pada garis spektrum minyak jelantah sesudah perlakuan memiliki garis yang lebih curam dari pada garis spektrum minyak jelantah sebelum perlakuan. Hal ini mengindikasikan adanya meningkatan konsentrasi pada senyawa dalam minyak jelantah sesudah perlakuan melewati membran poliamida/titanium dioksida/arang aktif kulit durian.

Berdasarkan penelitian Anisah, dkk[15], biodiesel dapat terbentuk dari proses esterifikasi pada minyak jelantah. Pengolahan minyak jelantah dapat diesterifikasi dengan proses fotokatalis menggunakan titanium dioksida. Pada Gambar 3 menunjukkan spektrum gugus fungsi C-O (1300-1500 $\mathrm{cm}^{-1}$ ) pada minyak sebelum dan sesudah perlakuan terjadi penurunan \%T. Penurunan \% $\mathrm{T}$ berbanding terbalik dengan jumlah konsentrasi. Hal ini mengindikasikan terjadi peningkatan senyawa dengan gugus fungsi C-O setelah perlakuan dengan melewati membran poliamida/titanium dioksida/arang aktif kulit durian.

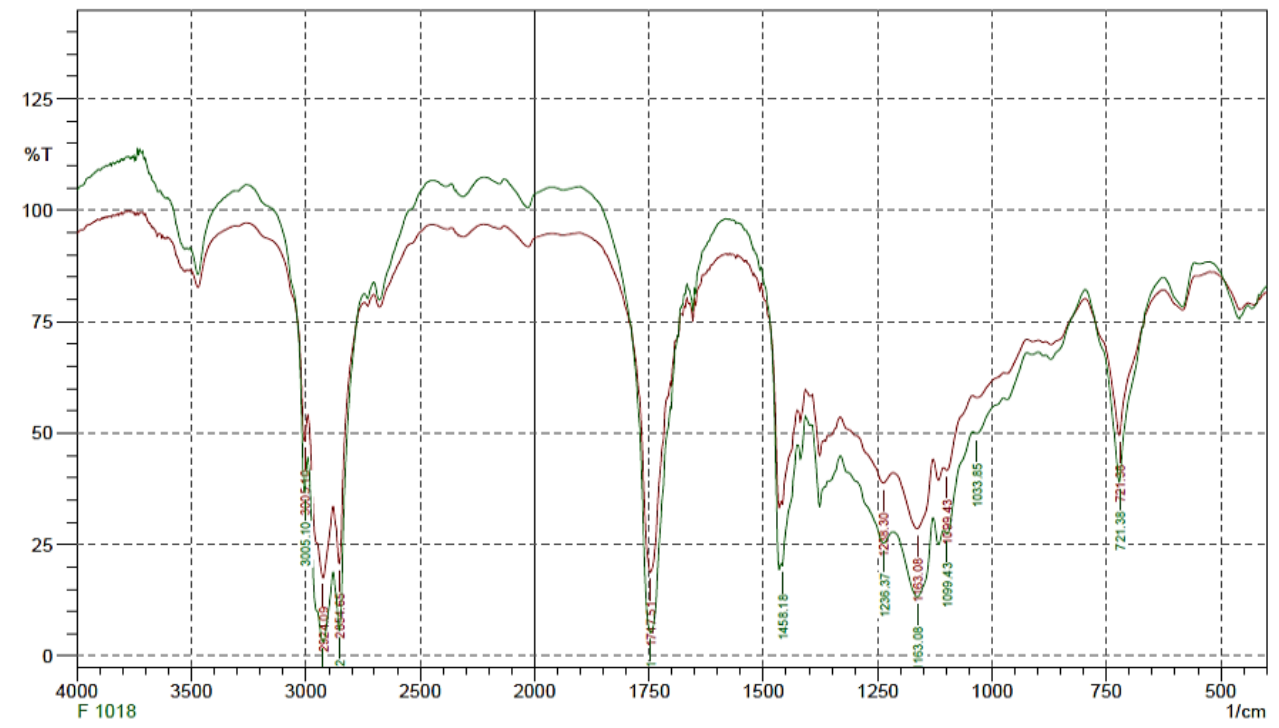

Gambar 3. (a) Aplikasi pengolahan minyak jelantah dengan menggunakan membran poliamida/ titanium dioksida/arang aktif kulit durian dalam lemari UV; (b) hasil pengolahan minyak jelantah.

Tabel 3. Hasil analisis gugus fungsi pada spektrum FTIR (Gambar 3)

\begin{tabular}{|c|c|c|c|c|c|}
\hline \multirow{2}{*}{ Area $\left(\mathrm{cm}^{-1}\right)$} & \multicolumn{2}{|c|}{$\begin{array}{c}\text { Minyak Jelantah } \\
\text { Sebelum Perlakuan }\end{array}$} & \multicolumn{2}{|c|}{$\begin{array}{c}\text { Minyak Jelantah } \\
\text { Sesudah Perlakuan }\end{array}$} & \multirow{2}{*}{$\begin{array}{c}\text { Karakteristik Gugus } \\
\text { Fungsi }\end{array}$} \\
\hline & $\begin{array}{c}\text { Angka } \\
\text { Gelombang }\end{array}$ & $\% \mathrm{~T}$ & $\begin{array}{c}\text { Angka } \\
\text { Gelombang }\end{array}$ & $\% \mathrm{~T}$ & \\
\hline $995-675$ & 721.38 & 49.488 & 721.38 & 38.95 & $\mathrm{C}-\mathrm{H}$ alkena \\
\hline $1300-1050$ & 1163.08 & 28.599 & 1163.08 & 13.26 & $\begin{array}{l}\mathrm{C}-\mathrm{O} \quad \text { (alkohol/eter/asam } \\
\text { karboksilat/ester) }\end{array}$ \\
\hline $1470-1340$ & - & - & 1458.18 & 20.29 & C-H alkana \\
\hline
\end{tabular}


Pada Tabel 3 menampilkan data spektrum minyak jelantah sebelum perlakuan dan sesudah perlakuan yang memiliki nilai \%T menurun. Untuk mendapatkan senyawa yang lebih spesifik, maka dilakukan uji GC-MS pada minyak jelantah sesudah perlakuan (minyak lapis optimum).

Berdasarkan perbandingan hasil analisis GC-MS pada Gambar 4 minyak jelantah sebelum perlakuan dan Gambar 5 minyak jelantah sesudah perlakuan didapatkan 2 puncak maksimal senyawa yang deteksi yaitu puncak ke 2 (waktu retensi 33.92 menit) dan ke 4 (waktu retensi 37.47 menit). Pada Tabel 4, minyak jelantah sesudah perlakuan menunjukkan penurunan $\%$ area pada puncak 2 dan peningkatan $\%$ area pada puncak 4 . Berdasarkan penelitian Buchori dan Widayat ${ }^{[16]}$, biodiesel memiliki penyusun utama yaitu senyawaan metil ester dan mendekati senyawa penyusun solar yaitu dengan komponen $\mathrm{C}_{10}-\mathrm{C}_{20}$. Pada waktu retensi puncak ke 2 mendekati pada struktur senyawa Metil 14-metilpentadekanoat $\left(\mathrm{C}_{17} \mathrm{H}_{34} \mathrm{O}_{2}\right)$ dan waktu retensi puncak ke 4 mendekati pada struktur senyawa Metil 11octadekenoat $\left(\mathrm{C}_{19} \mathrm{H}_{36} \mathrm{O}_{2}\right)$. Biodiesel memiliki penyusun utama yaitu senyawaan metil ester dan mendekati senyawa penyusun solar yaitu dengan komponen $\mathrm{C}_{10}-\mathrm{C}_{20}$. Berdasarkan 2 senyawa metil ester yang maksimal dihasilkan, maka minyak jelantah sesudah perlakuan memiliki kandungan yang menyerupai biodiesel. Penelitian ini diperlukan analisis lebih lanjut untuk dikembangkan sebagai media pengolahan minyak jelantah yang optimal dalam menghasilkan biodiesel.

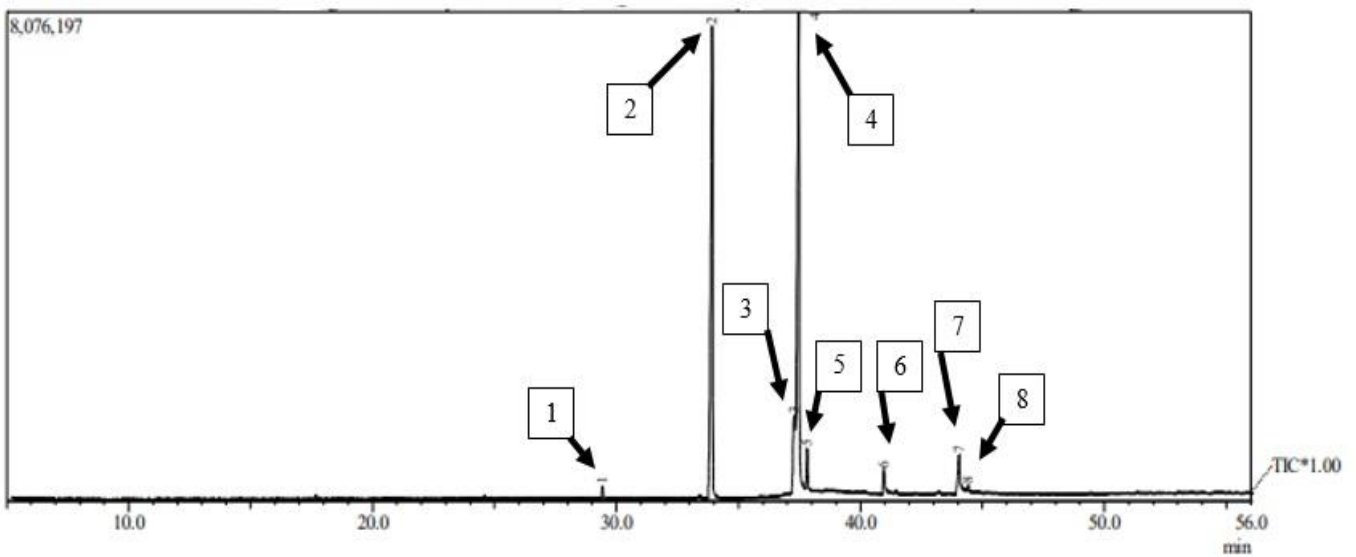

Gambar 4. Spektrum GC-MS dari minyak jelantah sebelum perlakuan.

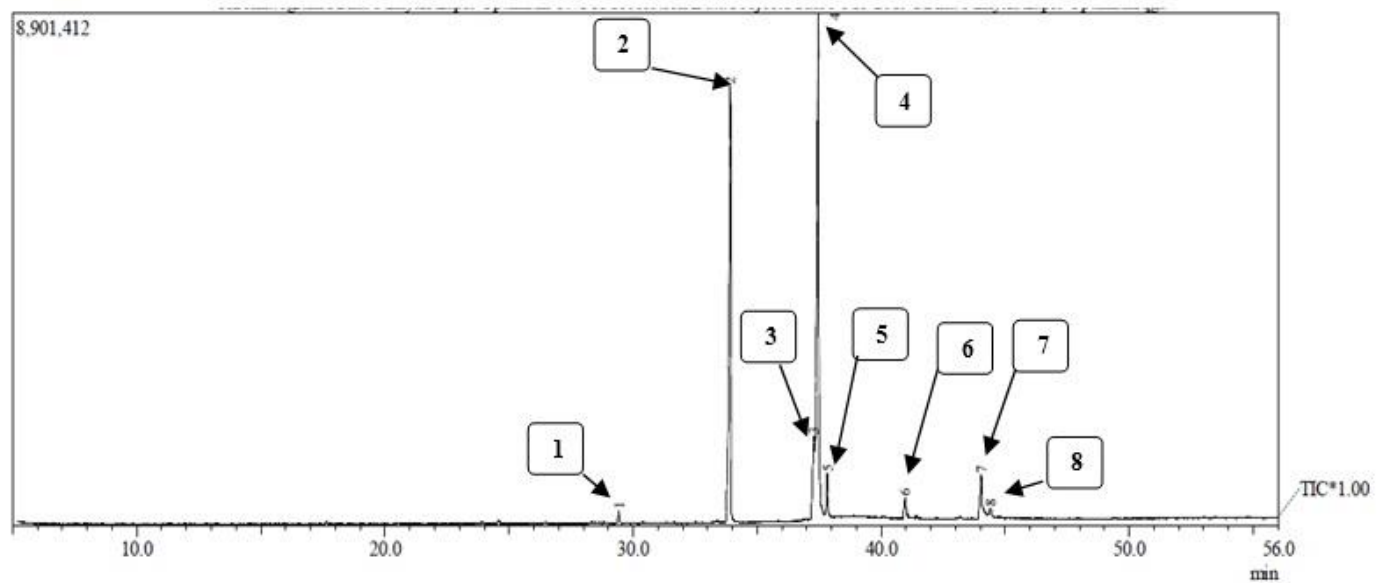

Gambar 5. Spektrum GC-MS dari minyak jelantah sesudah perlakuan. 
Tabel 4. Perbandingan tinggi puncak GC-MS minyak jelantah sebelum dan sesudah perlakuan

\begin{tabular}{ccccc}
\hline \multirow{2}{*}{ Puncak } & \multicolumn{2}{c}{ Minyak Jelantah Sebelum Perlakuan } & \multicolumn{2}{c}{ Minyak Jelantah Sesudah Perlakuan } \\
\cline { 2 - 5 } & Waktu Retensi (menit) & Area (\%) & Waktu Retensi (menit) & Area (\%) \\
\hline 1 & 29.43 & 0.70 & 29.43 & 0.72 \\
2 & 33.92 & 38.66 & 33.92 & 36.33 \\
3 & 37.29 & 7.06 & 37.29 & 7.31 \\
4 & 37.47 & 43.72 & 37.47 & 45.55 \\
5 & 37.82 & 2.98 & 37.82 & 2.74 \\
7 & 40.96 & 1.77 & 40.96 & 1.58 \\
8 & 44.05 & 4.39 & 44.05 & 4.97 \\
\hline
\end{tabular}

\section{Kesimpulan}

Berdasarkan pemaparan hasil penelitian dapat disimpulkan bahwa membran poliamida/ titanium dioksida/arang aktif kulit durian memiliki susunan membran komposit dengan kristal titanium dioksida yang teremban dalam bentuk anatase dan arang aktif yang berongga sehingga membran dapat mengadsorpsi secara optimal. Pengolahan minyak jelantah secara fotokimia menggunakan membran poliamida/titanium dioksida/arang aktif kulit durian dapat menurunkan asam lemak bebas hingga $33.75 \%$ dan bilangan peroksida hingga $18.33 \%$ dari kondisi semula. Minyak jelantah sesudah perlakuan (minyak 15 lapis) memiliki kriteria sebagai biodiesel jika dilihat dari massa jenis, kandungan asam lemak bebas, analisis gugus fungsi dan senyawa metil ester penyusunnya.

\section{Ucapan Terima Kasih}

Ucapan terima kasih ditujukan kepada Kementerian Riset dan Teknologi/Badan Riset dan Inovasi Nasional (KEMENRISTEK-BRIN) Republik Indonesia dalam pendanaan Penelitian Dosen Pemula Tahun Anggaran 2020.

\section{Daftar Pustaka}

1. Rengga, W. D. P., Karbon aktif: perpanjangan masa pakai minyak goreng. Deepublish, (2020).

2. Widayat., Suherman. \& Haryani, K., Optimasi proses adsorbsi minyak goreng bekas dengan adsorbent zeolit alam: studi pengurangan bilangan asam. J. Tek. Gelagar, 17(1): 77-82 (2006).

3. Badan Standardisasi Nasional., Minyak goreng sawit. 7709 (2012).

4. Standar Nasional Indonesia., Biodiesel. 7182 (2015).

5. Wulyoadi, S. \& Kaseno., Pemurnian minyak goreng bekas dengan menggunakan filter membran. in Seminar Nasional Rekayasa Kimia dan Proses 2004, 1-7 Universitas Diponegoro, (2004).

6. Ramdja, A. F., Febrina, L. \& Krisdianto, D., Pemurnian minyak jelantah menggunakan ampas tebu sebagai adsorben. J. Tek. Kim., 17(1): 7-14 (2010).

7. Yustinah. \& Hartini., Adsorbsi minyak goreng bekas menggunakan arang aktif dari sabut kelapa. in Prosiding Seminar Nasional Teknik Kimia "Kejuangan", B05-1B05-5 (2011). 
8. Dahlan, M. H., Siregar, H. P. \& Yusra, M., Penggunaan karbon aktif dari biji kelor dapat memurnikan minyak jelantah. J. Tek. Kim., 19(3): 44-53 (2013).

9. Rahayu, L. \& Purnavita, S., Pengaruh suhu dan waktu adsorpsi terhadap sifat kimiafisika minyak goreng bekas hasil pemurnian menggunakan adsorben ampas pati aren dan bentonit. J. Ilm. Momentum, 10(2): 35-41 (2014).

10. Mangallo, B., Efektivitas arang aktif kulit salak pada pemurnian minyak goreng bekas. Chem. Prog., 7(2): 58-65 (2014).

11. Masyithah, C., Aritonag, B. \& Gultom, E., Pembuatan arang aktif dari limbah kulit durian sebagai adsorben pada minyak goreng bekas untuk menurunkan kadar asam lemak bebas dan bilangan peroksida. J. Kim. Saintek dan Pendidik., II(2): 66-75 (2018).

12. Kaltsum, U., Kurniawan, A. F., Nurhasanah, I. \& Priyono, P., Reduction of peroxide value and free fatty acid value of used frying oil using $\mathrm{TiO} 2$ thin film photocatalyst. Bull. Chem. React. Eng. Catal.,
11(3): 369-375 (2016).

13. Safitri, R. E., Hayaati, R. S. R. \& Sartika, D., Effect of titanium dioxide mass on physical characteristics of polyamide/titanium dioxide/active charcoal of durian peels for waste cooking oil treatment. in The 4th International Conference on Mathematics and Science Education, 138-145 Universitas Negeri Malang, (2020).

14. Ibhadon, A. O. \& Fitzpatrick, P., Heterogeneous photocatalysis: recent advances and applications. Catalysts, 3(1): 189-218 (2013).

15. Anisah, P. M., Suwandi. \& Agustian, E., Effect of transesterification on the result of waste cooking oil conversion to biodiesel. in Journal of Physics: Conference Series, 1170(1): 012067 IOP Publishing, (2019).

16. Buchori, L. \& Widayat, W., Pembuatan biodiesel dari minyak goreng bekas dengan proses catalytic cracking. J. Tek., 28(2): 8392 (2007). 